\title{
Study of Traffic Management on Congested Intersections, By Redesign of Signal
}

\author{
Saurabh Sayre ${ }^{11}$, Dr. Prafull Wadhai ${ }^{2}$ Dr. B. V. Khode ${ }^{3}$
}

${ }^{* 1}$ MTech Scholar, Transportation Engineering, G H Raisoni College of Engineering, Nagpur, Maharashtra, India

${ }^{2}$ Associate Professor, Department of Civil Engineering, G H Raisoni College of Engineering, Nagpur, Maharashtra, India

${ }^{3}$ Professor, Department of Civil Engineering, G H Raisoni College of Engineering, Maharashtra, India

\begin{abstract}
Article Info

Volume 8, Issue 2

Page Number : 301-311

Publication Issue

March-April-2021

Article History

Accepted : 01 April 2021

Published : 03 April 2021

The use of traffic signals is the common practice in every cities having heavy traffic volume that is on clogged intersection. The signal phases are different at various intersections. The cycle time also differs as per traffic density at each intersection. Out somewhere it happens that there is green signal \& no vehicle on the route and despite that somewhere there is long queue although there is red signal. The proposed system first targets scattering any queue that was developed during red span and reduction in travel time. This study leads to the change in phases and redesign of present signal system, which not only gives a reduction in the queue length but also reduces travel time and decrease in fuel consumption. This change will positively results in improving traffic efficiency. Keywords : Traffic, Intersection, Congestion, Queue, Signal
\end{abstract}

\section{INTRODUCTION}

In India traffic is a troublesome issue in such urban zones. Road traffic is one of the major concerns in transportation. It has been seen that introducing impelled control methods from framework speculation into metropolitan activity, which is worthy over the development of the establishment in the city, is the valuable and gainful way to deal with improve the viability of metropolitan traffic running. Without a doubt, traffic blockages can have genuine unfavourable effects on people prosperity, step by step activities and individual fulfilment, coming to fruition into productive, regular and prosperity inconvenience for the Governments and affiliations. Intersection focuses are convergences of in any event two movement streams. They have a high centrality on account of the speed of incident event. Accordingly, the streaming representation of activity through them ought to be fittingly sorted out to guarantee a made sure about drive for street clients. Control over traffic on congested intersection has been huge issue in crowded zone. Congestion of traffic is paying extra time for the void roads in lights of red signal. Once in a while it happens that on a couple of roads straight going traffic is more than right turning yet the signal isn't giving honest to goodness value to that traffic, green signal grants both 
right and straight going together, in any case it exhausts time for straight going traffic. [1] Mahindra Deshmukh, et al. (2019) studied the passenger car unit (PCU) at different traffic densities ranging from somewhat low to clogged conditions. He found that there is no huge distinction between the field noticed qualities and those acquired from the model. He further states that 'the proposed methodology and simulation model is authentic'.[2]Chandan $\mathrm{K}$, et al. (2017) Authors proposed a unique algorithm for traffic state data estimation from GPS data and using fuzzy switching linear models. The employment of fluffy switches permits the portrayal of halfway traffic states, which provides more precise estimation of activity information contrasted with the traditional hard exchanging models, and so gives the capacity to propose better proactive and in-time choices.

[3]This paper gives the possibility of supplanting existing traffic lights with a framework to screen the traffic stream consequently in traffic lights where sensors are fixed in which the time feed is made dynamic and programmed by handling the live recognitions.[6] The proposed calculation is unsupervised and performs in sensible time, which inspires its convenience in. The calculation has been tried on open activity datasets gathered in England, 2014. The results of the trials are promising, with a most extreme supreme relative mistake of around $9 \%$. Be that because it's going to, more analyses are required to assess the execution of the calculation with versatile tests, either utilizing end-clients' cell phones or GPS-prepared vehicles.

\section{METHODOLOGY}

According to goals and objectives, step by step procedure adopted for this research work. The methodology adopted will come closer to the required results. The overall methodology is taken on the basis of literature review.

\section{Site Description}

The study was conducted on the busy intersections of Nagpur- Amravati highway, at Nagpur. Three intersections are taken for the study which is very congested in every peak hours. These intersections use traffic signal located and having fixed cycle time for each. During peak hours there is rush and suffer from traffic jams. The image below shows the study area. This study area is of total $2 \mathrm{~km}$ span. The public transports are more on it. As it is highway connected to the city the heavy vehicles are more and personal cars are also the part of the traffic. This highway is made up of flexible pavement and is of 6 lane highway having lane width 3 meters each. The traffic on the highway is heterogeneous like all over the India.

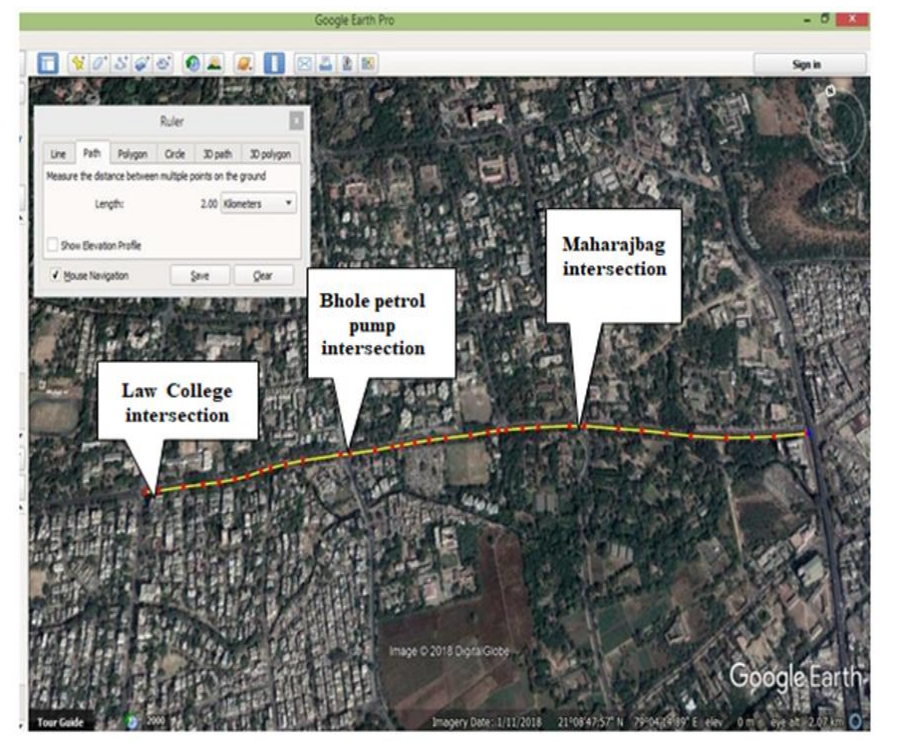

Fig -1: Google Earth Image Shows Study Area

\section{Work Flow Chart}

The following work flow chart is referred for the study of this particular work. 


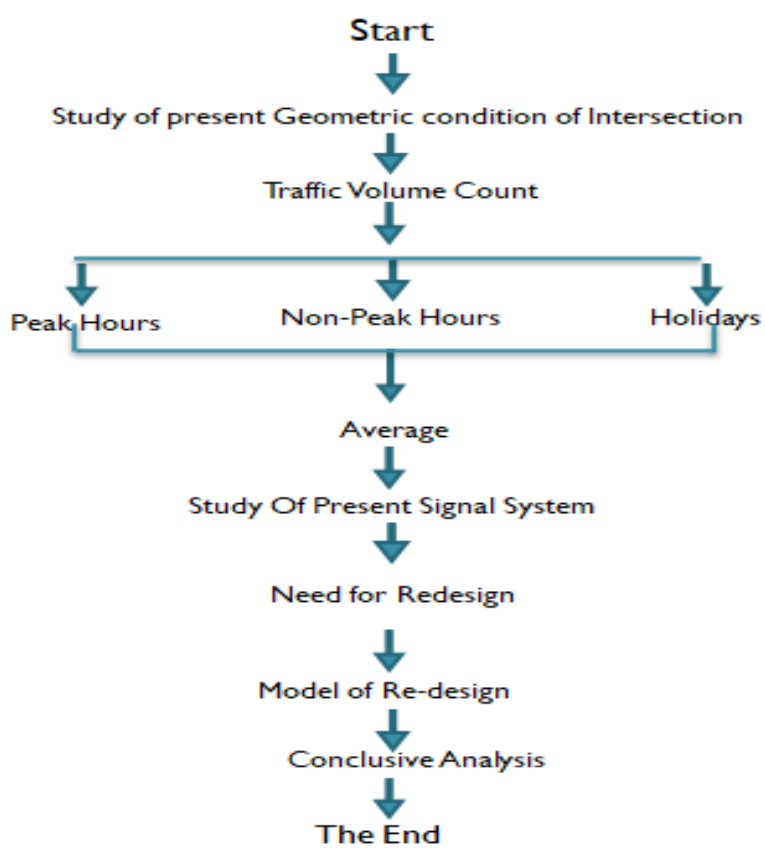

Chart -1: Work Flow Chart

\section{Study of Present Signal System}

The use of traffic signals of incompatible streams of vehicular and pedestrian traffic is vast in most of towns and cities. In Nagpur particularly in this study area the signal is fixed time signal. The Indian method is to have an amber period of 3 seconds as and transition interval between closing of related green movement and display of a red and indication or within termination of a red indication and initiation of related green movement. Here in this study area the green session and hence the cycle lengths are predetermined and of fixed duration. These types of signals are known of fixed time signals. The signal designs of these squares are dependent on the basis of the traffic volume count. The signal is four phase signal and green intervals are designed by considering the traffic volume on that particular intersection.
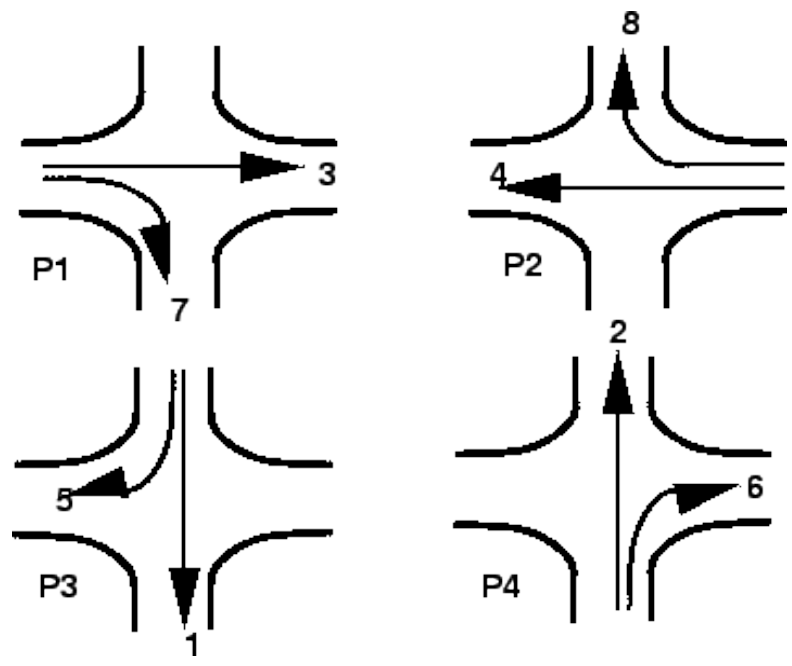

Fig -2: Existing Signal Phases

The phase system is shown in the figure. The left turning in this signal is always green that is allowed. The figure, it shows that the signal when turned into green it allows vehicles to go towards right and straight. The tables below shows the actual signalized system, the present signal system is fixed time signal time, with amber time $3 \mathrm{sec}$, at various intersections and the phases of those signals are as shown in above figure.

Table -1 : Existing Signal Intervals in Seconds

\begin{tabular}{|c|c|c|c|c|c|c|c|c|c|c|c|}
\hline \multicolumn{3}{|c|}{ Maharajbag Intersection } & \multicolumn{3}{c|}{ Bhole Pump Intersection } & \multicolumn{3}{c|}{ Law College Intersection } \\
\hline Phases & $\begin{array}{c}\text { Green } \\
\text { Time }\end{array}$ & $\begin{array}{c}\text { Red } \\
\text { Time }\end{array}$ & $\begin{array}{c}\text { Amber } \\
\text { Time }\end{array}$ & Phases & $\begin{array}{c}\text { Green } \\
\text { Time }\end{array}$ & $\begin{array}{c}\text { Red } \\
\text { Time }\end{array}$ & $\begin{array}{c}\text { Amber } \\
\text { Time }\end{array}$ & Phases & $\begin{array}{c}\text { Green } \\
\text { Time }\end{array}$ & $\begin{array}{c}\text { Red } \\
\text { Time }\end{array}$ & $\begin{array}{c}\text { Amber } \\
\text { Time }\end{array}$ \\
\hline I & 19 & 76 & 3 & I & 25 & 81 & 3 & I & 25 & 95 & 3 \\
\hline II & 18 & 77 & 3 & II & 24 & 82 & 3 & II & 32 & 88 & 3 \\
\hline III & 25 & 70 & 3 & III & 22 & 84 & 3 & III & 31 & 89 & 3 \\
\hline IV & 21 & 74 & 3 & IV & 26 & 80 & 3 & IV & 24 & 96 & 3 \\
\hline \multicolumn{3}{|c|}{ Cycle length=95 sec } & \multicolumn{3}{|c|}{ Cycle length 109 sec } & \multicolumn{3}{c|}{ Cycle length=123 sec } \\
\hline
\end{tabular}

\section{Data Collection}

The traffic using a road is composed of variety of vehicles ranging from simple peddles cycles to the motorcar and heavy commercial vehicles. Each type having an influence all the performance of the road in its own way, a simple volume count, without classifying the vehicles into distinct types is of limited 
use it is therefore the normal practice to classify the vehicles into distinct types when doing the volume counting.

There are various types or methods of volume count such as

- Manual methods

- Combination of Manual and Mechanical methods

- Automatic devices

- Moving Observer method

- Photographic methods

After studying all the types of data collection method the data collected for this work is by manual method, this method is preferred because it gives vehicle classification details with number of occupants; the data can be collected giving the details of traffic movement in each direction; specific vehicular moment such as left turns, right turns, straight ahead at a junction can be noted and recorded. Manual method enables any unusual conditions obtaining at the time of count to be recorded. This will help in understanding and analysing the traffic characteristics. Such unusual conditions can be adverse weather conditions traffic breakdown, temporary closer of any length of the highway for maintenance operations etc. The data collected by considering different parameters such as peak hours, non-peak hours, week days and holidays. The percentage of relative flow and total PCUs of all traffic volume count collected by considering above parameters is in the table below for different intersections.
Table -2(a) : Traffic Volume \& Percentage of Relative Flow at Maharajbag Intersection

\begin{tabular}{|c|c|c|c|c|}
\hline Parameters & $\begin{array}{c}\text { ROAD } \\
\text { DETAILS }\end{array}$ & $\begin{array}{l}\text { LEFT } \\
\text { GOING }\end{array}$ & $\begin{array}{c}\text { RIGHT } \\
\text { TURNING }\end{array}$ & $\begin{array}{l}\text { STRAIGHT } \\
\text { GOING }\end{array}$ \\
\hline \multirow{4}{*}{$\begin{array}{l}\text { Week Day, } \\
\text { Peak } \\
\text { Hours, } \\
\text { Morning } \\
\text { time }\end{array}$} & West-East & 1085 & 664 & 4340 \\
\hline & East-West & 889 & 1438 & 3583 \\
\hline & North-South & 1328 & 1789 & 2638 \\
\hline & South-North & 1252 & 732 & 1314 \\
\hline \multirow{4}{*}{$\begin{array}{l}\text { Week Day, } \\
\text { Non- Peak } \\
\text { Hours, } \\
\text { Afternoon } \\
\text { time }\end{array}$} & West-East & 469 & 222 & 2336 \\
\hline & East-West & 361 & 705 & 1452 \\
\hline & North-South & 662 & 894 & 1354 \\
\hline & South-North & 554 & 332 & 695 \\
\hline \multirow{4}{*}{$\begin{array}{c}\text { Weekend, } \\
\text { Holiday }\end{array}$} & West-East & 215 & 115 & 1404 \\
\hline & East-West & 259 & 332 & 821 \\
\hline & North-South & 337 & 443 & 789 \\
\hline & South-North & 281 & 204 & 336 \\
\hline \multirow{4}{*}{$\begin{array}{c}\text { Week Day, } \\
\text { Peak } \\
\text { Hours, } \\
\text { Holiday } \\
\end{array}$} & West-East & 378 & 290 & 2020 \\
\hline & East-West & 280 & 625 & 1257 \\
\hline & North-South & 527 & 668 & 1216 \\
\hline & South-North & 510 & 289 & 592 \\
\hline
\end{tabular}

\begin{tabular}{|c|c|c|}
\hline \multicolumn{3}{|c|}{ Average Volume Count } \\
\hline & $\begin{array}{c}\text { Total } \\
\mathrm{PCU} / \mathrm{hr}\end{array}$ & $\begin{array}{l}\text { Relative } \\
\text { Flow \% }\end{array}$ \\
\hline \multicolumn{3}{|c|}{ West - East } \\
\hline Left & 537 & 16.5 \\
\hline Right & 323 & 9.9 \\
\hline Straight & 2395 & 73.6 \\
\hline \multicolumn{3}{|c|}{ East - West } \\
\hline Left & 447 & 14.9 \\
\hline Right & 775 & 25.82 \\
\hline Straight & 1778 & 59.27 \\
\hline \multicolumn{3}{|c|}{ North - South } \\
\hline Left & 714 & 23.11 \\
\hline Right & 949 & 30.73 \\
\hline Straight & 1425 & 46.16 \\
\hline \multicolumn{3}{|c|}{ South - North } \\
\hline Left & 645 & 36.62 \\
\hline Right & 390 & 21.96 \\
\hline Straight & 734 & 41.41 \\
\hline
\end{tabular}

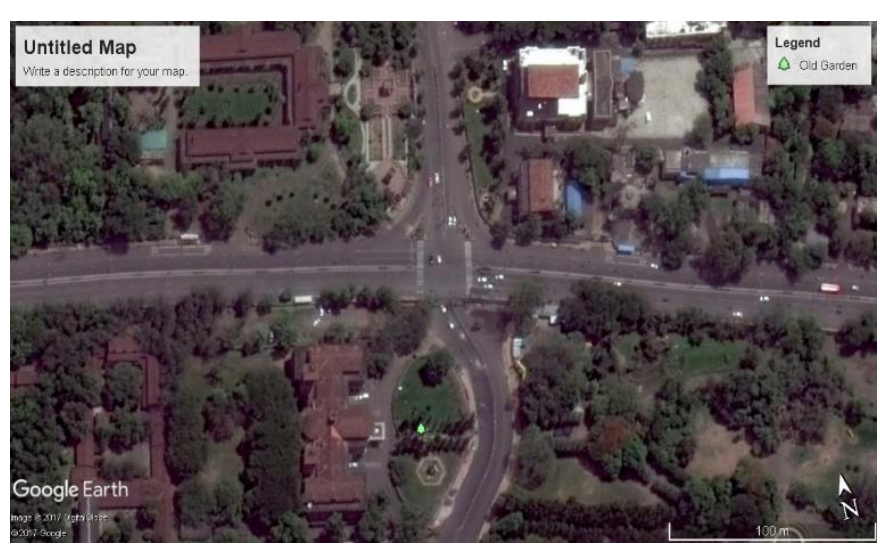

Fig -3(a): Maharajbag Intersection 
Table -2(b) : Traffic Volume \& Percentage of Relative Flow at Bhole Petrol Pump Intersection

\begin{tabular}{|c|c|c|c|c|}
\hline Parameters & $\begin{array}{c}\text { ROAD } \\
\text { DETAILS }\end{array}$ & $\begin{array}{l}\text { LEFT } \\
\text { GOING }\end{array}$ & $\begin{array}{l}\text { RIGHT } \\
\text { TURNING }\end{array}$ & $\begin{array}{l}\text { STRAIGHT } \\
\text { GOING }\end{array}$ \\
\hline \multirow{4}{*}{$\begin{array}{l}\text { Week Day, } \\
\text { Peak } \\
\text { Hours, } \\
\text { Morning } \\
\text { time } \\
\end{array}$} & West-East & 575 & 732 & 3651 \\
\hline & East-West & 657 & 256 & 2993 \\
\hline & North-South & 379 & 1132 & 2748 \\
\hline & South-North & 575 & 1510 & 2186 \\
\hline \multirow{4}{*}{$\begin{array}{l}\text { Week Day, } \\
\text { Non- Peak } \\
\text { Hours, } \\
\text { Afternoon } \\
\text { time }\end{array}$} & West-East & 280 & 359 & 1830 \\
\hline & East-West & 293 & 131 & 1508 \\
\hline & North-South & 170 & 510 & 1664 \\
\hline & South-North & 284 & 236 & 678 \\
\hline \multirow{4}{*}{$\begin{array}{c}\text { Weekend, } \\
\text { Holiday }\end{array}$} & West-East & 114 & 176 & 945 \\
\hline & East-West & 143 & 73 & 1188 \\
\hline & North-South & 142 & 482 & 1120 \\
\hline & South-North & 219 & 192 & 341 \\
\hline \multirow{4}{*}{$\begin{array}{c}\text { Week Day, } \\
\text { Peak } \\
\text { Hours, } \\
\text { Holiday }\end{array}$} & West-East & 280 & 359 & 1830 \\
\hline & East-West & 775 & 745 & 1691 \\
\hline & North-South & 170 & 510 & 1664 \\
\hline & South-North & 284 & 236 & 678 \\
\hline
\end{tabular}

\begin{tabular}{|c|c|c|}
\hline \multicolumn{3}{|c|}{ Average Volume Count } \\
\hline & Total PCU/hr & $\begin{array}{c}\text { Relative Flow } \\
\%\end{array}$ \\
\hline \multicolumn{3}{|c|}{ West - East } \\
\hline Left & 319 & 11.44 \\
\hline Right & 406 & 14.56 \\
\hline Straight & 2064 & 73.60 \\
\hline \multicolumn{3}{|c|}{ East - West } \\
\hline Left & 467 & 17.87 \\
\hline Right & 301 & 11.52 \\
\hline Straight & 1845 & 70.61 \\
\hline \multicolumn{3}{|c|}{ North - South } \\
\hline Left & 215 & 8.05 \\
\hline Right & 658 & 24.63 \\
\hline Straight & 1799 & 67.33 \\
\hline \multicolumn{3}{|c|}{ South - North } \\
\hline Left & 340 & 18.35 \\
\hline Right & 543 & 29.30 \\
\hline Straight & 970 & 52.35 \\
\hline
\end{tabular}

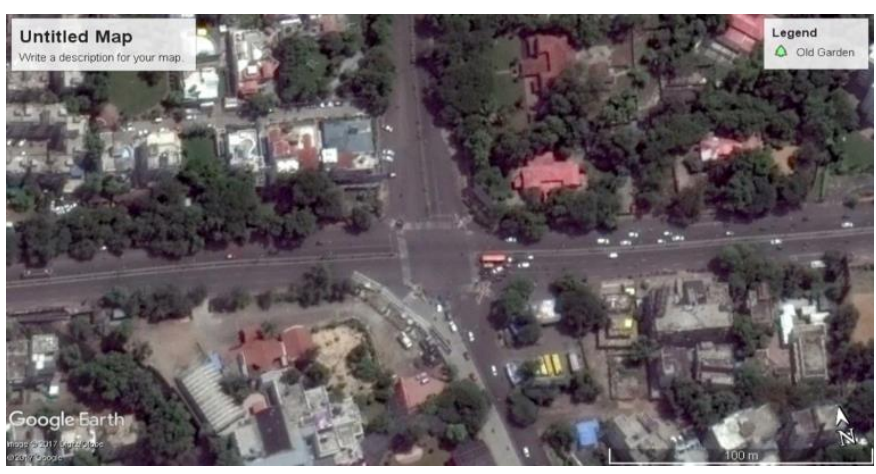

Fig -3(b): Bhole Petrol Pump Intersection
Table -2(c): Traffic Volume \& Percentage of Relative Flow at Law College Intersection

\begin{tabular}{|c|c|c|c|c|}
\hline Parameters & $\begin{array}{c}\text { ROAD } \\
\text { DETAILS }\end{array}$ & $\begin{array}{c}\text { LEFT } \\
\text { GOING }\end{array}$ & $\begin{array}{c}\text { RIGHT } \\
\text { TURNING }\end{array}$ & $\begin{array}{c}\text { STRAIGHT } \\
\text { GOING }\end{array}$ \\
\hline \multirow{4}{*}{$\begin{array}{l}\text { Week Day, } \\
\text { Peak Hours, } \\
\text { Morning } \\
\text { time }\end{array}$} & West-East & 1068 & 1390 & 2651 \\
\hline & East-West & 1945 & 1503 & 3719 \\
\hline & North-South & 826 & 1842 & 3045 \\
\hline & South-North & 559 & 2135 & 3543 \\
\hline \multirow{4}{*}{$\begin{array}{l}\text { Week Day, } \\
\text { Non- Peak } \\
\text { Hours, } \\
\text { Afternoon } \\
\text { time }\end{array}$} & West-East & 1753 & 716 & 1425 \\
\hline & East-West & 361 & 705 & 1452 \\
\hline & North-South & 377 & 818 & 1573 \\
\hline & South-North & 275 & 1146 & 1750 \\
\hline \multirow{4}{*}{$\begin{array}{c}\text { Weekend, } \\
\text { Holiday }\end{array}$} & West-East & 1233 & 349 & 724 \\
\hline & East-West & 747 & 505 & 1527 \\
\hline & North-South & 224 & 464 & 1242 \\
\hline & South-North & 217 & 915 & 1454 \\
\hline \multirow{4}{*}{$\begin{array}{c}\text { Week Day, } \\
\text { Peak Hours, } \\
\text { Holiday }\end{array}$} & West-East & 1177 & 781 & 1596 \\
\hline & East-West & 775 & 745 & 1691 \\
\hline & North-South & 365 & 737 & 1697 \\
\hline & South-North & 216 & 1108 & 1780 \\
\hline
\end{tabular}

\begin{tabular}{|c|c|c|}
\hline \multicolumn{3}{|c|}{ Average Volume Count } \\
\hline & Total PCU/hr & $\begin{array}{c}\text { Relative Flow } \\
\%\end{array}$ \\
\hline \multicolumn{3}{|c|}{ West - East } \\
\hline Left & 1307 & 35.20 \\
\hline Right & 808 & 21.76 \\
\hline Straight & 1598 & 43.04 \\
\hline \multicolumn{3}{|c|}{ East - West } \\
\hline Left & 956 & 24.41 \\
\hline Right & 864 & 22.06 \\
\hline Straight & 2097 & 53.54 \\
\hline \multicolumn{3}{|c|}{ North - South } \\
\hline Left & 448 & 13.57 \\
\hline Right & 965 & 29.22 \\
\hline Straight & 1889 & 57.21 \\
\hline \multicolumn{3}{|c|}{ South - North } \\
\hline Left & 316 & 8.37 \\
\hline Right & 1326 & 35.14 \\
\hline Straight & 2132 & 56.49 \\
\hline
\end{tabular}

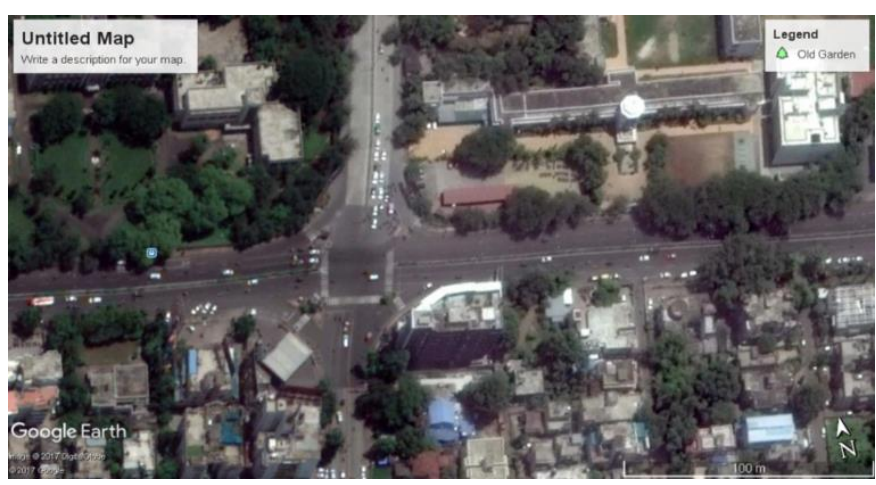

Fig -3(c): Law College Intersection 


\section{Need for Re-Design}

The above traffic volume count gives information about the volume per hour in PCU's and it is clear from data collection is that the straight going traffic is more at all the intersections and as compared to that the right going traffic is very less. Because of less volume of right going traffic and that signal phases it causes delay for the straight going traffic. The delay is occurring for the every straight going traffic at every intersection. To avoid this delay it is necessary to redesign those signals as per current requirements. The change in the phases is also needed. The present signal system is causing the avoidable delay. For the fixed time signals we have to require careful settings.

\section{Re-Design of Signal}

As per the necessity the signal is required to be redesigned. Webster's model is used for that, in the redesign we make changes into phase. The design is four phase but the directions when signal is green must be changed as shown in the figure, it allows only the straight going traffic from both directions of opposite lanes, it causes less delay and proper coordination will results into time consume. It can provide for an orderly movement of traffic and can increase the traffic handling capacity of the intersection.
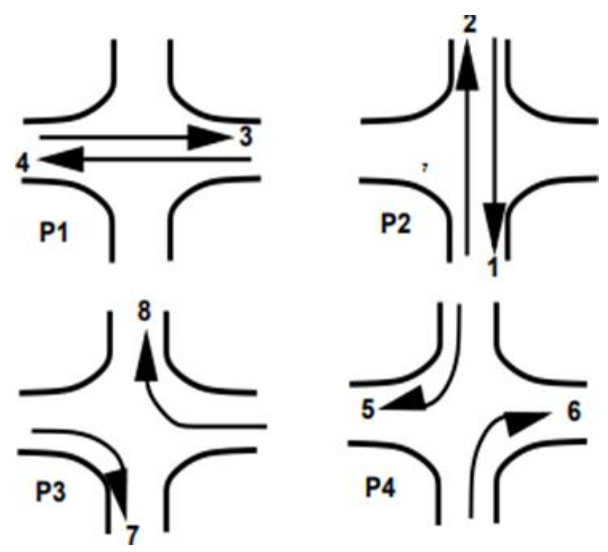

Fig -4: Proposed Signal Phases

\section{Determination of Optimum Cycle Length}

One of the important steps in designing a fixed time signal system is to determine the cycle time. If cycle time is short, the ratio of the time lost will be greater resulting incompetent signal operation and longer delays. On the other hand if the cycle time is more, the proportion of time lost to cycle time will be less, and the signal operation will be more productive. Simultaneously, if the process duration is too large, there should be threat that a decent meeting of the green time will be utilized by unsaturated progression of traffic, which again prompts failure. For each traffic stream volume there is an ideal process duration which brings about the base deferral to the vehicle .It will be seen there in that for process duration inside the scope of $3 / 4$ to one-and-a-half times they ideal worth. The deferral is never more than $10-20 \%$ over that given by the ideal process duration. By separating the condition for the all-out deferral of the convergence as for process duration, the accompanying condition for the ideal process duration has been acquired Cycle time calculation.

$$
\mathrm{C}=\left[\mathrm{N}^{*} \mathrm{Tl}\right] /[1-(\mathrm{Vc} / \mathrm{S})]
$$

Where,

\section{$\mathrm{N}$ - Number of lanes}

$\mathrm{T}$ l- the sum of start-up lost time and clearance lost time (considered as 3sec)

Vc- Critical volume count (PCU/Hr)

(Vehicle volume count, specifying Right turning and straight going vehicles)

$$
\mathrm{S}=3600 / \mathrm{h}
$$

Where,

S- The saturation flow rate in vehicles per hour.

$\mathrm{h}$ - The saturation headway in seconds (Range 1.5-

\section{- Determination of Total Green Time}

Total Green time $\mathrm{Tg}=\mathrm{C}-\mathrm{N}(\mathrm{Tl})$

Where,

C- Calculated cycle time $\mathrm{N}$ - number of lanes

Tl- the sum of start-up lost time and clearance lost time (considered as 3sec)

\section{- Green Time per Lane}

Per lane green time is calculated by multiplying the ratio of total volume of that lane to the total volume with total green time calculated. 


\section{$\mathrm{G} 1=(\mathrm{Vc} 1 / \mathrm{Vc})^{*} \mathrm{Tg}$}

By following the above steps the signals are redesigned, as shown in the table below for the particular intersections.

Table -3: Re-designed Signal Intervals in Seconds

\begin{tabular}{|c|c|c|c|c|c|c|c|c|c|c|c|}
\hline \multicolumn{4}{|c|}{ Maharajbag Intersection } & \multicolumn{4}{|c|}{$\begin{array}{l}\text { Bhole petrol pump } \\
\text { Intersection }\end{array}$} & \multicolumn{4}{|c|}{ Law college Intersection } \\
\hline Phases & $\begin{array}{l}\text { Green } \\
\text { Time }\end{array}$ & $\begin{array}{l}\text { Red } \\
\text { Time }\end{array}$ & $\begin{array}{l}\text { Ambe } \\
\text { Time }\end{array}$ & Phases & $\begin{array}{l}\text { Green } \\
\text { Time }\end{array}$ & $\begin{array}{l}\text { Red } \\
\text { Time }\end{array}$ & $\begin{array}{l}\text { Amber } \\
\text { Time }\end{array}$ & Phases & $\begin{array}{l}\text { Green } \\
\text { Time }\end{array}$ & $\begin{array}{l}\text { Red } \\
\text { Time }\end{array}$ & $\begin{array}{l}\text { Amber } \\
\text { Time }\end{array}$ \\
\hline I & 31 & 91 & 3 & I & 46 & 90 & 3 & I & 33 & 81 & 3 \\
\hline II & 37 & 85 & 3 & II & 53 & 82 & 3 & II & 36 & 78 & 3 \\
\hline III & 20 & 102 & 3 & III & 11 & 125 & 3 & III & 15 & 99 & 3 \\
\hline IV & 25 & 97 & 3 & IV & 17 & 119 & 3 & IV & 21 & 93 & 3 \\
\hline \multicolumn{4}{|c|}{ Cycle length $=125 \mathrm{sec}$} & \multicolumn{4}{|c|}{ Cycle length $=139 \mathrm{sec}$} & \multicolumn{4}{|c|}{ Cycle length $=117 \mathrm{sec}$} \\
\hline
\end{tabular}

\section{Modeling And Simulation}

According to our study we have examined that PTV VISSIM is an ideal tool and we have used it for our work. The 'Google Earth' software is also used for the background image of the particular intersection. The following steps are followed for the modelling of the signals at these intersections for the present signal system and the proposed signal system.

\subsection{Background Image}

Using "Google Earth" software from Google, the background image of the intersection and overall study area is presented in the image format. These images are used for the VISSIM simulations. The image below is showing the study with span $2 \mathrm{~km}$.

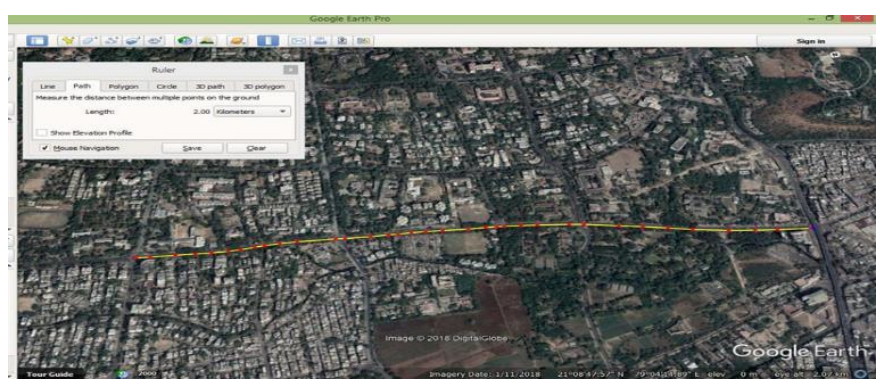

\subsection{Link Formation}

After inserting the background image on the VISSIM software, the links which are shown on that particular image are dragged by using the tool "link" on the tool bar option. The roads are dragged with the measured lane width and number of lanes. At intersection all the four lanes are connected by the connections and links are formed with all the details.

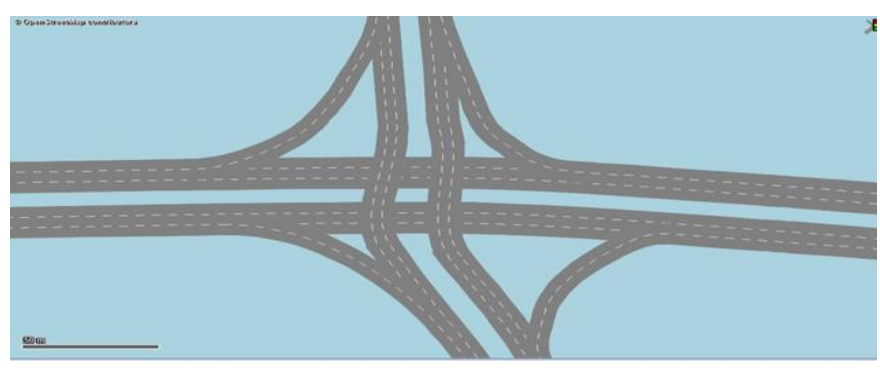

Fig -5(b): Links Formed on VISSIM Software

\subsection{Vehicle Inputs and Routing}

The vehicle input is given at the left side roads, according to the data collected in the format of Relative flow. The relative flow will differ from the vehicle routes and vehicle types. All the vehicle input is in PCUs/hr. After the vehicle input the routes are specified on the drawn links accordingly. Relative Flow for the vehicle routes is the ration of left going or straight going or right turning vehicles to the total vehicles in PCUs. In the same way the relative flow for the types of vehicle is also the ratio of type of vehicle to the total number of vehicles. The relative flow is the ratio, has no unit but also can be considered in percentage.

\subsection{Signal Program}

The signal is designed manually and implemented on VISSIM software, the phases are considered in the given format. The signal design is mainly depend upon the cycle time and the green intervals. The amber time is $3 \mathrm{sec}$ for all the intersection. Following are the images showing the signal phase design.

Fig -5(a): Study Area, ‘Google Earth’ Image 


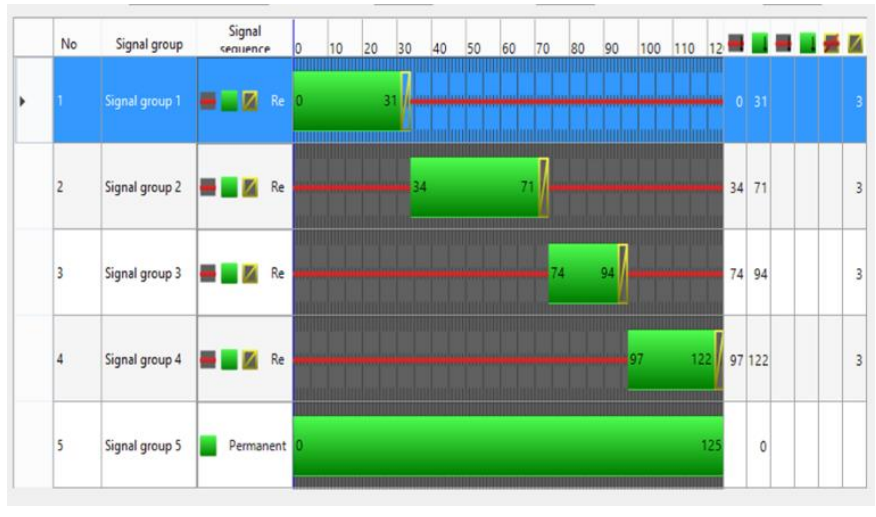

Fig -6(a): Image Showing Signal Timings at All Four Phases at Maharajbag Intersection.

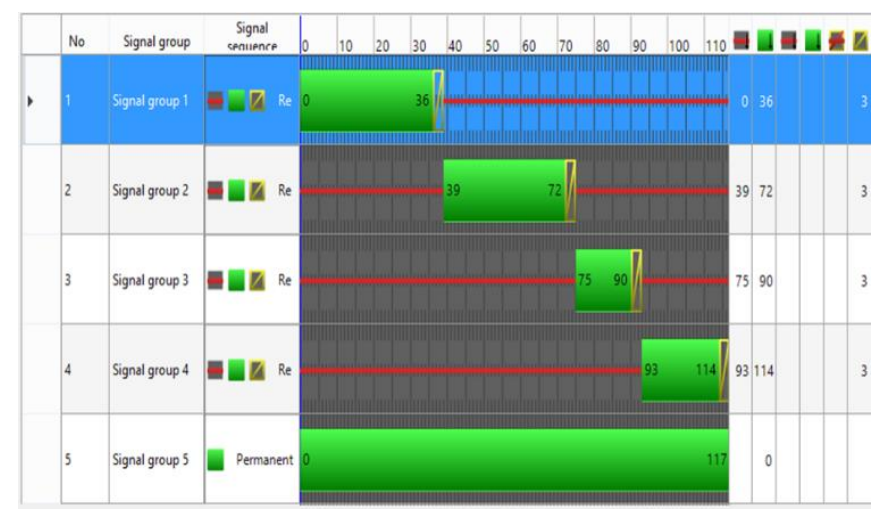

Fig -6(b): Image Showing Signal Timings at All Four Phases at Bhole Petrol Pump Intersection.

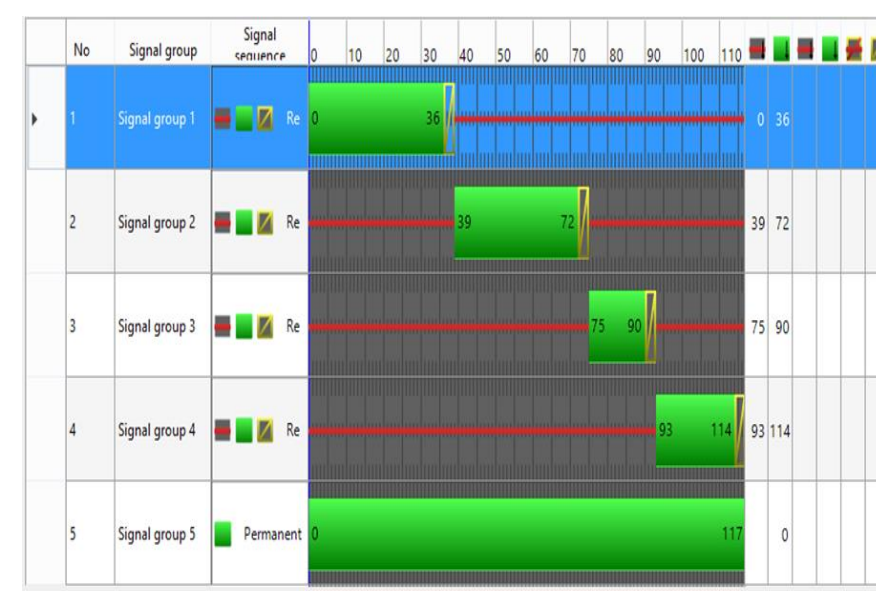

Fig -6(c): Image Showing Signal Timings at All Four Phases at Law College Intersection.

\subsection{Node Evaluation}

The intersection is ready for the evaluation of the result after placing the signal heads on the particular locations. That particular area is considered as a node and taken for the study. After that node evaluation the results are obtained.

\section{DISCUSSION}

According to survey done for the data collection it is observed that the straight going traffic is more at every intersection than the right turning traffic. To provide more comfort for those more number of straight going traffic the redesign is done. The queue length on the intersections is calculated using VISSIM software, the queue length differs from the current signal conditions and redesigned signal. The queue length is calculated using node analysis on VISSIM software. On each lane, length of vehicle in meters is shown in the table below, and the difference between existing signal system and redesigned signal system is shown in the graphical as well as in the tabular format of each intersection. The details of lane with their numbers are also shown in figure. The following are the graphs showing queue length difference between current situation of signal and the proposed signal system.

\section{Maharajbag Intersection}

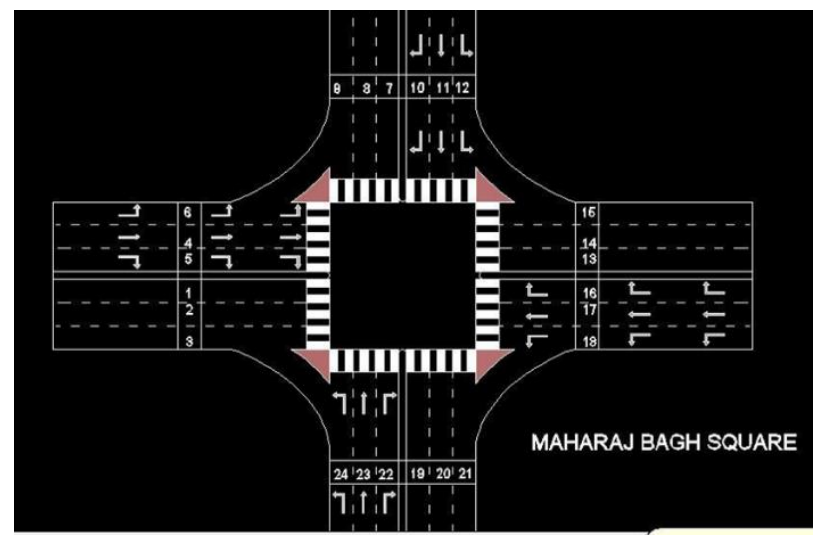

Fig -7: Lane Numbers at Maharajbag Intersection 
Table-4 : Queue Length of Existing Signal System and Proposed Signal at Maharajbag Intersection

\begin{tabular}{|c|c|c|}
\hline & \multicolumn{2}{|c|}{ Q- Length (meters) } \\
\hline \multirow{2}{*}{ Movement } & Existing signal & Proposed signal \\
\hline $4 .-14$ & 87.19 & 15.02 \\
\hline $5 .-19$ & 87.19 & 72.59 \\
\hline $6 .-9$ & 87.19 & 0.00 \\
\hline $10-1$ & 56.94 & 52.07 \\
\hline $11-20$ & 56.94 & 3.50 \\
\hline $12-15$ & 56.94 & 0.00 \\
\hline $16-7$ & 116.52 & 108.87 \\
\hline $17-2$ & 116.52 & 10.44 \\
\hline $18-21$ & 116.52 & 0.00 \\
\hline $22-13$ & 48.71 & 25.69 \\
\hline $23-8$ & 48.71 & 35.90 \\
\hline $24 .-3$ & 48.71 & 0.00 \\
\hline
\end{tabular}

The graph below showing the queue length difference between existing signal system and the proposed redesigned signal system. On $\mathrm{X}$ - axis vehicle routes are specified and on the $\mathrm{Y}$ - axis length in meters is shown.

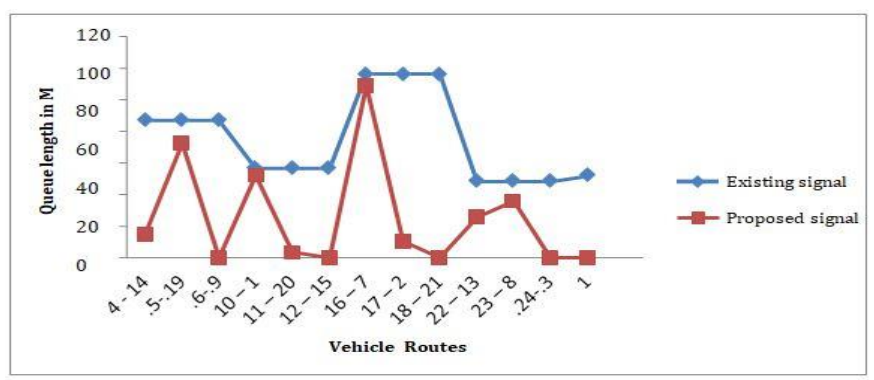

Chart -2: Difference in the Queue Length in Graphical Format at Maharajbag Intersection

\section{Bhole Petrol Pump Intersection}

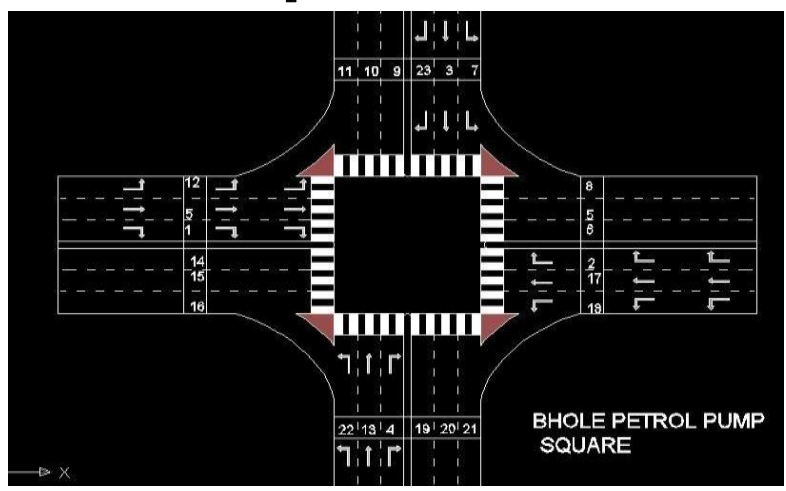

Fig -8: Lane Numbers at Bhole Petrol Pump Intersection
Table-5: Queue Length of Existing Signal System and Proposed Signal at Bhole Petrol Pump Intersection

\begin{tabular}{|c|c|c|}
\hline & \multicolumn{2}{|c|}{ Q- Length (meters) } \\
\hline Movement & $\begin{array}{c}\text { Existing } \\
\text { signal }\end{array}$ & $\begin{array}{c}\text { Proposed } \\
\text { signal }\end{array}$ \\
\hline $1-19$ & 54.50 & 35.04 \\
\hline $2-9$ & 54.50 & 15.15 \\
\hline $3-20$ & 54.50 & 42.54 \\
\hline $4-6$ & 69.13 & 46.37 \\
\hline $5-5$ & 69.13 & 51.16 \\
\hline $7-8$ & 69.13 & 0.00 \\
\hline $12-11$ & 55.00 & 0.00 \\
\hline $13-10$ & 55.00 & 26.65 \\
\hline $17-15$ & 55.00 & 32.54 \\
\hline $18-21$ & 16.10 & 0.00 \\
\hline $22-16$ & 16.10 & 0.00 \\
\hline $23-14$ & 16.10 & 11.26 \\
\hline
\end{tabular}

The above table shows the difference between the queue lengths in meters. The difference is very large in number. The change in the signal design will gives the positive results.

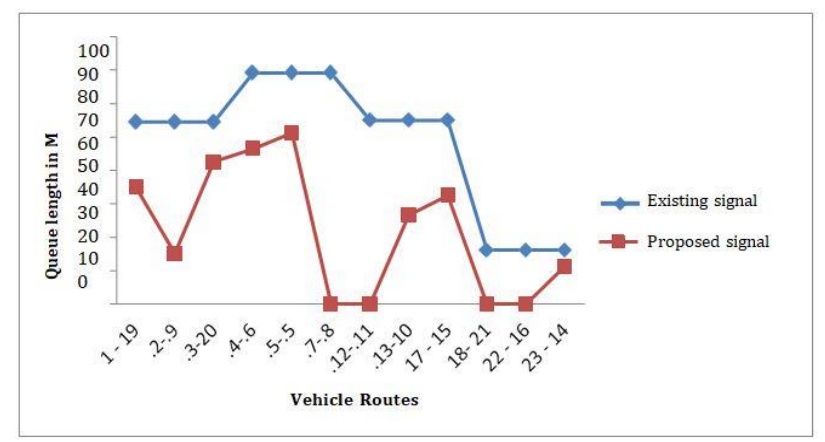

Chart -3: Difference in the Queue Length in Graphical Format at Bhole Petrol Pump Intersection

\section{Law College Intersection}

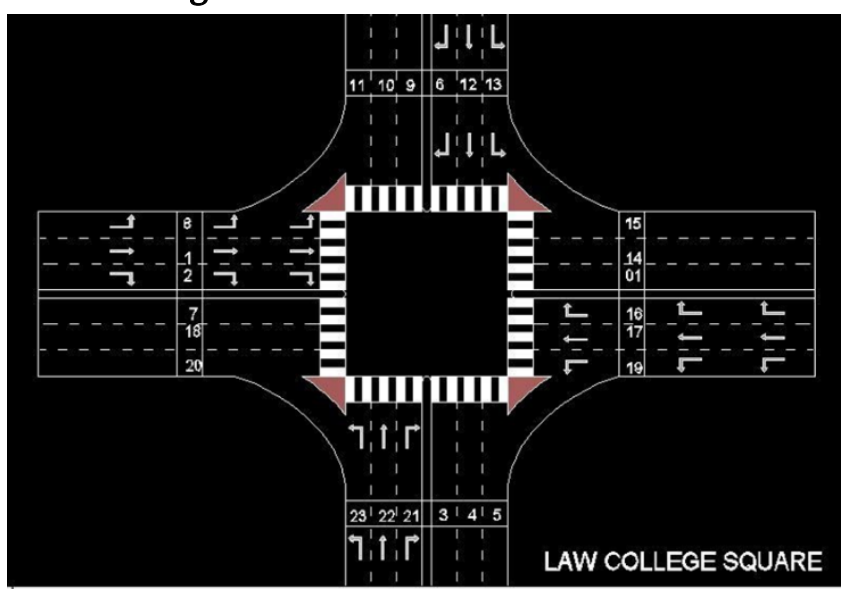

Fig -9: Lane Numbers at Law College Intersection 
Table-6: Queue Length of Existing Signal System and Proposed Signal at Law College Intersection

\begin{tabular}{|c|c|c|}
\hline & \multicolumn{2}{|c|}{ Q- Length (meters) } \\
\hline Movement & $\begin{array}{c}\text { Existing } \\
\text { signal }\end{array}$ & $\begin{array}{c}\text { Proposed } \\
\text { signal }\end{array}$ \\
\hline $1-1$ & 68.61 & 56.75 \\
\hline $2-3$ & 68.61 & 50.81 \\
\hline $6-7$ & 68.61 & 49.68 \\
\hline $8-11$ & 54.34 & 0.00 \\
\hline $12-4$ & 54.34 & 34.20 \\
\hline $13-15$ & 54.34 & 0.00 \\
\hline $16-9$ & 106.84 & 61.70 \\
\hline $17-18$ & 106.84 & 83.14 \\
\hline $19-5$ & 106.84 & 0.00 \\
\hline $21-14$ & 61.71 & 37.02 \\
\hline $22-10$ & 61.71 & 32.09 \\
\hline $23-20$ & 61.71 & 0.00 \\
\hline
\end{tabular}

In the table above the difference in the queue lengths is shown, in the existing queue length there is a large value than the re-designed signal system. Somewhere there is value of queue length is zero in the left turning vehicles.

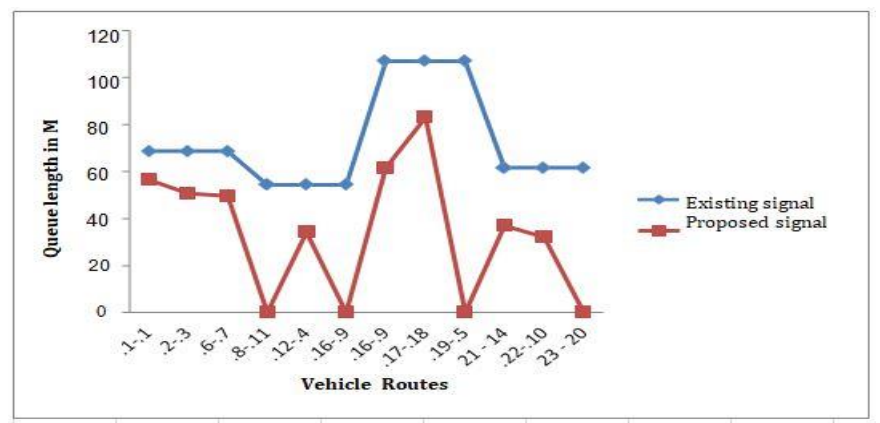

Chart -4: Difference in the Queue Length in Graphical Format at Law College Intersection

In India there is a heterogeneous traffic conditions, two key issues of heterogeneous traffic, namely, multiple vehicle types and non-lane based movement. As the traffic of existing road system in the cities grows, congestion becomes serious problem. Medium and long term solutions like widening of roads, providing elevated flyovers and constructing bypass and urban expressways are costly. As the use of traffic signals for control of conflicting streams of vehicular and pedestrian traffic is extensive in most of the towns and cities here in our case also it is used.

\section{RESULTS AND CONCLUSIONS}

After redesign signal on those squares the following conclusions were obtained. For the application of the phases on site it is necessary to mark the directions on the road so that the vehicles will follow the route and the re-designed signal will succeed.

- The queue length difference between existing and redesigned signal system is considerable, it reduces $40-45 \%$.

- The above redesigned model of signal able to predict delays reasonably well, the delay reduced to $45-50 \%$ from the existing scenario, indicating the efficiency of the modelling approach, even in the heterogeneous traffic.

- They can provide orderly movement of vehicles accordingly, left, straight or right turning.

- We can enhance the traffic-handling capacity of the intersection through appropriate geometric layouts.

- The redesigned signals are used to interrupt heavy straight going traffic from all the four lanes at intervals is permitted.

If it seems to be essential to coordinated to provide constant or nearly constant movement of traffic at a certain speed along a given path should also be done.

\section{REFERENCES}

[1]. Mahindra Deshmukh, Dr. Ashish Dhamaniya 2, Dr Bhalchandra Khode 3 'Estimation of Capacity, Passenger Car Unit and Level of Service of an urban arterial using microsimulation technique'.

[2]. Chandan, K., Seco, A. M., \& Silva, A. B. (2017). Real-time traffic signal control for isolated intersection, using car-following logic under connected vehicle environment. Transportation research procedia, 25, 1610-1625. 
[3]. Sharma, I., \& Pardeep, K. G. (2015). Study of automatic traffic signal system for chandigarh.

[4]. Ali, M. H., Kurokawa, S., \& Shafie, A. A. (2013). Autonomous road surveillance system: A proposed model for vehicle detection and traffic signal control. Procedia Computer Science, 19, 963-970.

[5]. Siddharth, S. M. P., \& Ramadurai, G. (2013). Calibration of VISSIM for Indian heterogeneous traffic conditions. Procedia-Social and Behavioral Sciences, 104, 380-389.

[6]. Bhatkar, A. A., Patil, M. P., \& Gulghane, M. A. A. Comparative study of Traffic Management using Traffic Signal Automations at Signalized Intersections on Congested Highway.

[7]. IRC 93:1985 Guidelines for Design of Signalized Road Intersections, Indian Roads Congress, New Delhi, India, 1985

[8]. Specification for road traffic signals, IS: 75371974, Indian Standard institution, New Delhi, 1975.

\section{Cite this article as :}

Saurabh Sayre, Dr. Prafull Wadhai, Dr. B. V. Khode, "Study of Traffic Management on Congested Intersections, By Redesign of Signal", International Journal of Scientific Research in Science and Technology (IJSRST), Online ISSN : 2395-602X, Print ISSN : 2395-6011, Volume 8 Issue 2, pp. 301-311, March-April 2021. Available at doi : https://doi.org/10.32628/IJSRST1218247

Journal URL : https://ijsrst.com/IJSRST1218247 